\title{
REAVIVAMENTO DE PATRIMÔNIO HISTÓRICO EM ADAMANTINA: UMA PROPOSTA CULTURAL
}

Aline Akie Santos Mizuno, Fabrícia Dias de Moraes Fernandes Borges

Universidade do Oeste Paulista - UNOESTE, curso de Arquitetura e Urbanismo, Presidente Prudente, SP. Email: aline mizuno@hotmail.com

\section{RESUMO}

O presente artigo consiste em estudar a arquitetura de um patrimônio histórico da cidade de Adamantina, sendo ele o edifício do antigo Cine Santo Antônio, por meio de levantamentos bibliográficos para enfatizar sua importância e conceituar um novo uso para a edificação sem comprometer suas características originais. Relata-se também, acerca da importância de um Centro de Cultura para uma cidade e a sua correlação com a mesma, onde promove consigo, uma cultura inclusiva, a qual todos possuem direito a ela dentro de um espaço arquitetônico histórico, resgatando a memória do mesmo, de forma a construir laços entre diferentes grupos sociais da cidade. Partindo da proposta para um Centro de Cultura que exerce a função de atrair a sociedade para manter a cultura viva e presente, foram elaborados estudos teóricos referentes à temática. Portanto, de acordo com a referente pesquisa, é possível constatar a importância de exercer atividades culturais através de um instrumento essencial, a arquitetura.

PALAVRAS-CHAVE: Patrimônio Histórico; Centro de Cultura; Cultura inclusiva; Memória; Arquitetura.

\section{REVIVAL OF HISTORICAL PATRIMONY IN ADAMANTINE: A CULTURAL PROPOSAL}

\section{ABSTRACT}

The present article consists of an architecture of a historical patrimony of the city of Adamantina, being the building of the old Cine Santo Antônio, through bibliographical surveys to emphasize its importance and to conceptualize a new use for a building without compromising its original characteristics. It is also related to the importance of a Center of Culture for a city and its correlation with one, where it promotes with it an inclusive culture, one all human rights in the area of a historical architectural space, rescuing a memory of the same, in order to build links between different social groups in the city. Starting from the proposal for a Culture Center that has a function of attracting a society to maintain a culture alive and present, theoretical studies on the subject have been elaborated. By an essential method, an architecture.

Keywords: Historical Patrimony; Center of Culture; Inclusive culture; Memory; Architecture.

\section{INTRODUÇÃO}

A cultura e a memória são essencialmente relevantes para o crescimento sociocultural de uma sociedade, e é a arquitetura um dos principais instrumentos que enaltece esses dois importantes construtos sociais através da sua relação com o espaço físico. Desta forma, a história de uma cidade está inteiramente ligada ao acesso da memória coletiva e do patrimônio arquitetônico, questões que infelizmente tem caído em esquecimento. E é neste momento que edifícios contemporâneos tomam os lugares de edifícios antigos que fizeram a história e memória da cidade da sociedade, deixando as mesmas esquecidas pela população existente e futuras gerações. 
Segundo Somekh (2015, p. 9), "Saber preservar e identificar a história das cidades é um esforço coletivo que depende da participação dos cidadãos, mas deve ser coordenada pelo poder público", portanto, é essencial essa participação da sociedade para a conservação de edifícios históricos, que tem como objetivo permanecer a memória da população viva, porém, é de suma importância a sociedade entender o que é preservar e por quê devemos preservar.

Um questionário por meio eletrônico, referente ao antigo Cine Santo Antônio foi realizado, a fim de justificar a escolha do tema proposto, onde a sociedade tivesse o direito de expressar suas opiniões referentes ao antigo prédio que atualmente encontra-se em desuso e abandono. Esse questionário resultou na falta em que os moradores sentem tanto da função como cinema, como de um espaço cultural acessível para todos os tipos de faixas etárias e camadas sociais, onde todos possam ter direito a aulas de música, artes, teatro, cinema, entre outros. Como o edifício é um marco da cidade, tanto para a população de Adamantina como para região, dar este novo uso é uma forma da memória da população ser mantida viva.

O objetivo principal é incentivar a cultura para uma população que tanto carece desse importante construto social, acessível para todos os tipos de faixas etárias e camadas sociais, com a intenção de criar laços entre a comunidade usuária.

\section{METODOLOGIA}

A metodologia desenvolvida para a elaboração do presente artigo foi fundamentada através de levantamentos bibliográficos, com aprofundamentos teóricos de acordo com o tema a ser abordado e suas conclusões. A visita técnica no local estudado foi essencial para entender melhor a problemática deste patrimônio histórico da cidade de Adamantina, trazendo consigo também levantamentos fotográficos para melhor compreensão.

\section{RESULTADOS}

Para Neves (2012), centros de cultura, são responsáveis por trazer conhecimento através de atividades tanto para aprender como para criar. Por isso, o centro cultural é um local onde torna-se possível construir vínculos com a sociedade e os fatos locais, sendo utilizado como um equipamento informacional, que propaga a cultura para diferentes camadas sociais e faixas etárias, a fim de estabelecer a inclusão.

O conceito de Centro Cultural pode ser estabelecido de acordo com o seu uso e suas atividades. Não existe uma imposição sobre qual uso abrigar, podendo ser um espaço de múltiplo uso, como espaço para leitura, oficinas de arte e música, apresentações teatrais, musicais e cinematográficas, entre outras atividades. (NEVES, 2013). Portanto, não há um padrão a ser seguido ao projetar um Centro Cultural, o seu uso pode variar conforme o programa de necessidades, mas desde que seu uso não venha beneficiar à apenas um público alvo, pois o intuito de um Centro Cultural é a inclusão social.

Neves (2013, p. 2) define um espaço cultural como "instituições criadas com o objetivo de se produzir, elaborar e disseminar práticas culturais e bens simbólicos". Mas essa cultura vivenciada deve assegurar-se com a realidade local, ou seja, a mesma deve obter laços com a comunidade usuária e seus acontecimentos. No entanto, um centro cultural não pode ser considerado apenas como um espaço de lazer, mas este deve ser considerado como um local onde acontece uma série de atividades em benefício do crescimento conceitual de uma determinada população.

Segundo Neves (2013, p. 5), "os centros culturais brasileiros, diante de uma diversidade da produção, possibilitam identificar quatro formas: a grande construção; a restauração; o remendo; e a mistura grossa". Então, pode-se atribuir características para as quatro formas, a começar pela grande construção, que é estabelecida conforme a decisão do Estado, pois exige um alto investimento, sendo uma arquitetura de destaque; a segunda forma, a restauração, ligada à 
intervenção em um edifício histórico, sendo um ponto característico para a cidade por sua construção antiga, cabendo ao arquiteto conservar a preservação e funcionalidade; o remendo dirige a instalação de um centro cultural para um espaço qualquer que não tenha mais uso, sendo reformado para ser um espaço útil de ser abrigado; e por fim, a mistura grossa, que refere-se tanto a falta de recursos como de espaço físico, e desta forma, as atividades culturais acontecem em edifícios que já ocorrem outros tipos de atividades.

Desta forma, o intuito dos centros culturais, é a integração de três importantes campos do trabalho cultural, sendo eles, a criação, onde estimula a produção de bens culturais, através de oficinas, cursos, laboratórios, etc., a circulação desses bens culturais, para que os eventos não tornem um espaço destinado apenas a lazer, e por último a preservação da área do trabalho cultural, conservando um bem cultural e suporte da memória coletiva. (NEVES, 2013).

Portanto, é de extrema importância a relação de um espaço cultural com a cidade, sabendo que este espaço deva condizer com a realidade da população, pois será um espaço tanto para propagar a cultura como para ensinar e aprender. Sendo assim, não se pode fazer uma cultura diferente da realidade da qual a sociedade vivencia, por isso, o centro cultural tem o papel de se relacionar com a população e os fatos que existem dentro dela. (RAMOS, 2007). O direito à cultura hoje em dia, torna-se mais acessível para todos os tipos de faixas etárias e classes sociais, mas o que dificulta o acesso dos usuários é o incentivo e disseminação da mesma.

No Brasil, nos últimos anos, os centros culturais ganharam grande proporção, pelo fato de promoverem até mesmo as cidades na qual estão inseridos, pois, geralmente são implantados em locais de fácil acesso para população. Por isso, é essencial a participação da sociedade nas atividades existentes, sendo que as mesmas não são designadas somente para conhecimento informacional sobre cultura, mas para proporcionar também distração e agregação entre a população de todas as classes sociais e faixas etárias de uma dada cidade. Portanto, a maioria desses centros culturais são situados em lugares estratégicos que tencionam para um crescimento da cidade e trazendo melhorias tanto para o bairro local como do entorno. Gerando também a reiteração de locais considerados deteriorados, agregando de forma cultural com as comunidades. (NEVES, 2013).

\section{DISCUSSÃO}

De acordo com o material disponibilizado pelo engenheiro da prefeitura de Adamantina, o Cine Santo Antônio foi criado seis anos após o a inauguração do primeiro cinema da região, o Cine Adamantina, sendo aprovado seu projeto em 1952 e inaugurado em 1954, 17 anos após a chegada dos primeiros habitantes do município, idealizado também por Ângelo Francisco Zonta, ocupando os lotes 12 e 13 da quadra 52, na Alameda Armando de Sales Oliveira, número 449, com área total de $1.030 \mathrm{~m}^{2}$ e capacidade para 1250 pessoas.

Segundo Barbosa (2016), o antigo Cine Santo Antônio era administrado inicialmente pela organização "Amigos da Cultura", que tinha por objetivo garantir a população direito à cultura, portanto, tinham o dever de garantir a estabilidade do cinema, para que o mesmo não fechasse.

Alguns anos após a inauguração do Cine Santo Antônio, instalou-se na loggia do antigo cinema, um trailer de cachorro-quente, denominado "Lanche da Irma", o qual permanece até os dias atuais no mesmo lugar, mantendo ainda de certa forma, a memória da população ativa sobre o patrimônio.

De acordo com Barbosa (2016), há relatos que o cinema não estava adquirando recursos suficientes para o manter ativado, e com a estréia do filme "Titanic", com um recorde de telespectadores, o cinema conseguiu se reerguer e saiu do crédito e passou para o débito. Porém, tais recursos não foram suficientes e por isso, acarretou seu fechamento.

Desativado há mais de 10 anos, a parte do foyer foi reaberta, mas como um bar, que logo em seguida foi fechado novamente e desde então o antigo Cine Santo Antônio encontra-se em 
processo de venda, porém, sem nenhuma manutenção e conservação dos responsáveis e conscientização da população. Ainda permanece notável, mesmo em estado de abandono, por sua grandiosa arquitetura ter um valor histórico, pois é uma das primeiras construções existentes na cidade de Adamantina, e também pelo trailer de cachorro-quente. $O$ cinema estabeleceu um marco não somente na cidade de Adamantina, como em toda região, pois como era um dos únicos cinema da região, recebia telespectadores de diversas cidades vizinhas.

Pela sua má conservação, a população não se importa com o estado atual em que encontra-se o edifício, e por isso, durante a semana em horários de expediente, motos são estacionadas na loggia, pessoas fazem da fachada do cinema local para anúncios, colando cartazes e rabiscando portas e paredes externas, o tornando ainda mais abandonado pela população.

Um edifício que ganhou um grande destaque e causou um grande impacto por ser um dos primeiros cinemas de rua inaugurado no município de Adamantina ainda existente e que possui suas características originais até os dias atuais. Com as marcas do tempo impressas sobre o prédio, podemos presenciar um pouco da história de Adamantina ainda viva não somente na memória dos antigos moradores da região, como de presentes gerações. Porém, pelo seu atual estado de abandono e má conservação, sem a conscientização dos responsáveis e da população, influi para que se degrade cada vez mais.

FIGURA 1 - Fachada do antigo Cine Santo Antônio de Adamantina.

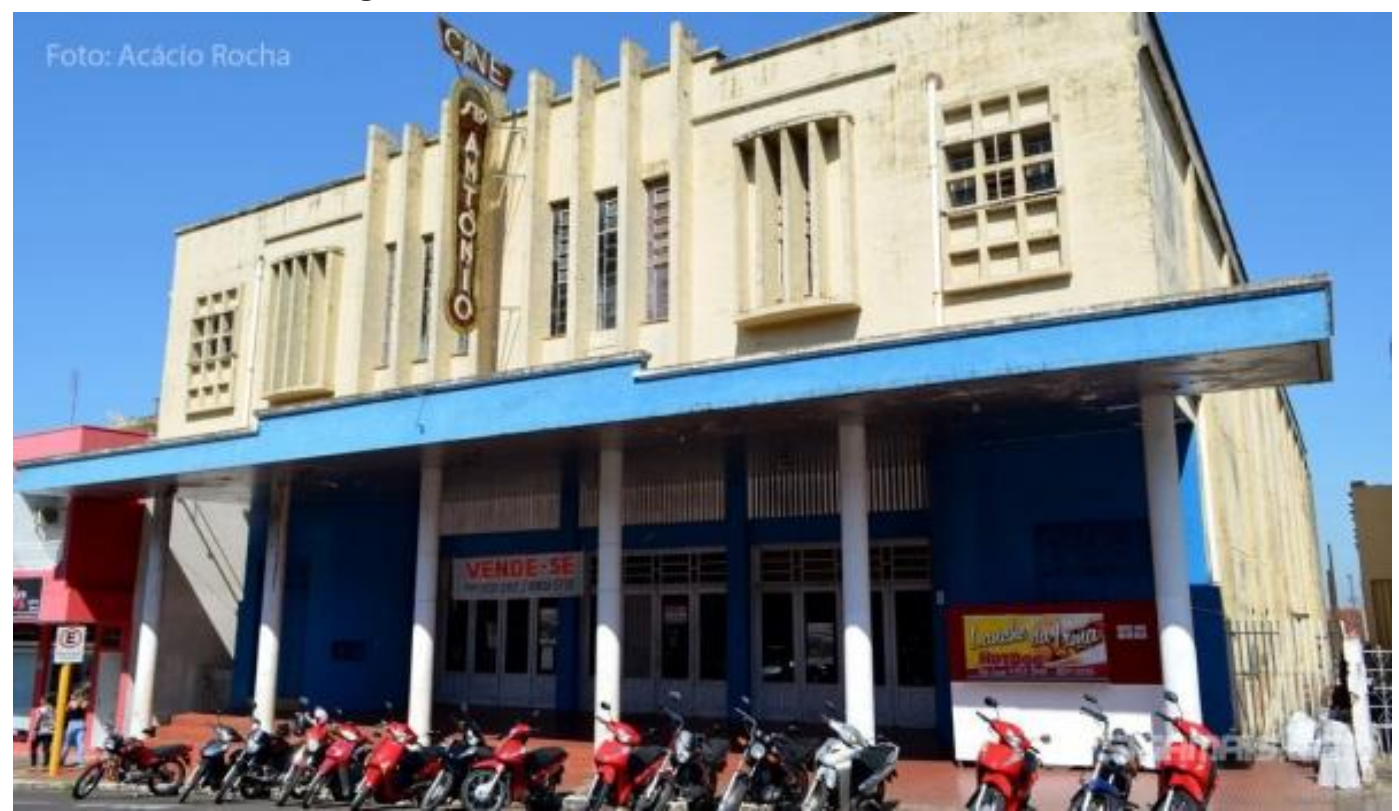

Fonte: Imagem por Acácio Rocha. Disponível em: <http://www.sigamais.com/colunas/cronicasprovincianas/quotno-escurinho-do-cinemaquot/>.

\section{CONCLUSÃO}

Podemos concluir que o verdadeiro significado de um centro de cultura, abrange a questão de a cultura ser viva, ou seja, sempre presente na vida de cada indivíduo, de forma a incentivar e propagar a cultura para a sociedade.

Portanto, o papel principal do centro cultural em uma cidade, é o de difundir a cultura tanto para os indivíduos que já são cultos, como principalmente para indivíduos que não tiveram a oportunidade e o incentivo de vivenciar a cultura de perto. E através desse incentivo, crianças crescem sabendo da importância da cultura, jovens recebem oportunidades para o mercado de trabalho e idosos garantem um espaço na cultura a qual os pertecem também. Deste modo, quanto maior o número de pessoas a serem influenciadas pela cultura, menor será o número de 
pessoas que praticam atos ilíticos, sejam eles as drogas, o preconceito, a marginalidade, entre outros.

Por fim, ao relacionar a memória popular com o acesso a cultura através da reabertura do Cine Santo Antônio como um espaço de disseminação cultural e reavivamento do patrimônio histórico cultural, dar-se-a a oportunidade de reviver a cultura que fora esquecida com a desativação do local e, consequentemente, o aumento cognitivo da população através da cultura.

\section{REFERÊNCIAS BIBLIOGRÁFICAS}

BARBOSA, S. “No escurinho do cinema...". Crônicas provincianas. 11 de novembro de 2016. Disponível em: <http://www.sigamais.com/colunas/cronicas-provincianas/quotno-escurinho-docinemaquot/>. Acesso em: 20 mai. 2017.

NEVES, R. R. Centro Cultural: a Cultura à promoção da Arquitetura. Especialize, Goiânia, v. 01, n. 005, jul., 2013. Disponível em: <https://www.ipog.edu.br/revista-especialize-online/edicao-n52013/?setarParametros=true\&pagingPage=10\&>. Acesso em: 14 mai. 2017.

RAMOS, L. B. Centro Cultural: Território privilegiado da ação cultural e informacional na sociedade contemporânea. Disponível em: <http://www.cult.ufba.br/enecult2007/lucieneborgesramos.pdf>. Acesso em: 20 mai. 2017.

SOMEKH, N. Preservando o Patrimônio Histórico: um manual para gestores municipais. Conselho de Arquitetura e Urbanismo de São Paulo, 2015. Disponível em: <http://www.causp.gov.br/wpcontent/uploads/2015/11/Manual-Patrimonio_completo_baixa.pdf> Acesso em: 14 fev. 2017. 